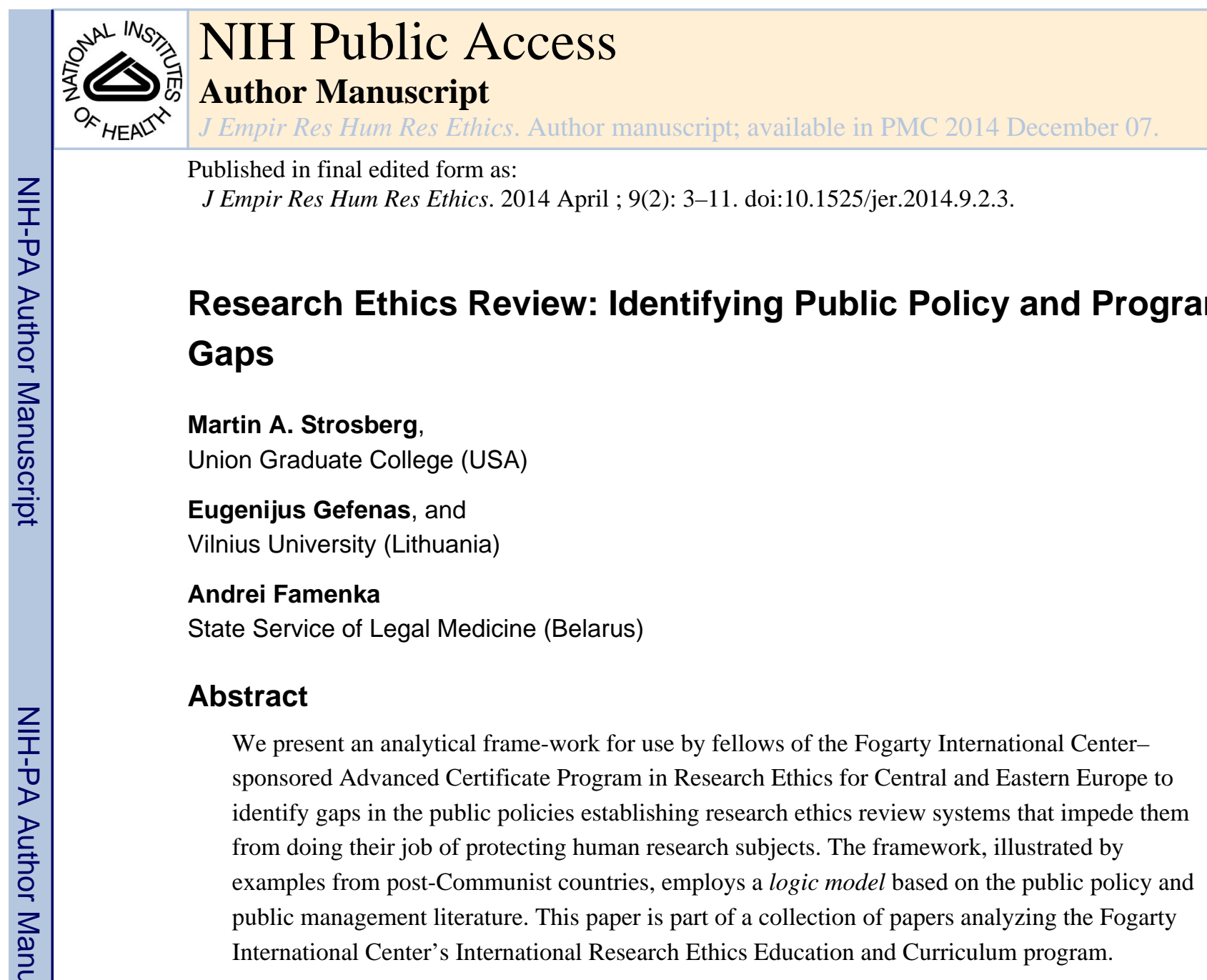

\title{
Keywords
}

research ethics; public policy; capacity building; training

Efforts to build research ethics capacity have mostly concentrated on strengthening the research ethics committee (REC), which is viewed as the primary vehicle for protecting human research subjects. To this end, the Advanced Certificate Program in Research Ethics for Central and Eastern Europe, like other Fogarty International Center (FIC) programs, trains its fellows to be research ethicists capable of serving on RECs. The Advanced Certificate Program also emphasizes public policymaking and in particular the identification of gaps in the policies establishing research ethics systems that impede RECs from doing their job of protecting human research subjects. In this paper we present a framework from the public policy and public management literature for identifying these gaps based on an understanding of the public policymaking process and how research ethics policy is formulated, implemented, and managed. Identifying such gaps is a necessary first step in repairing them. Attention in the program curriculum to the public policymaking process and the identification of policy gaps is intended not only to guide those fellows who conduct

(C) 2014 by joan sieber. all rights reserved.

Please address communication to: Martin A. Strosberg, Center for Bioethics and Clinical Leadership, Union Graduate College, 80 Nott Terrace, Schenectady, NY 12308. Phone: 518-631-9896. strosbem@uniongraduatecollege.edu. 
analyses of their research ethics review systems but to increase the awareness of those who go on to serve on RECs, oversight and regulatory agencies, and on advocacy, educational, and professional bodies dedicated to human subjects protection. The aim is to facilitate change at the institutional, national, and even international level.

Research ethics review for the protection of human subjects must be understood in relation to the larger context in which it is embedded. In this regard Hyder et al. (2009) conceptualize research ethics review as systemically linked to: (1) national and regional strategies (e.g., legal and regulatory authority for RECs, national guidelines, budget priority for research ethics, investment in training and capacity building); (2) institutional commitment (e.g., organizational structures and procedures, conformity with national and regional laws and guidance); and (3) researcher's conduct (e.g., respect for government, institution, REC). Surrounding this system are enabling conditions including a strong civil society, public accountability, and trust in basic transactional processes, which are in turn surrounded by development conditions including political freedoms, economic facilities, social opportunities, and transparency guarantees.

\section{The public policymaking process}

Public policy is the purposive course of action followed by government to influence behavior, achieve a set of objectives, or ameliorate a problem (e.g., mistreated or unprotected research subjects). The public policymaking process is commonly cast as a series of stages or phases. In Figure 1, it is modeled as an iterative sequence of policy formulation, implementation, and modification (Longest, 2010).

Policy formulation is divided into two distinct parts: agenda setting followed by legislation development. In agenda setting, individuals and groups bring problems and possible solutions to the attention of government decision makers (Kingdon, 1995). With the right political conditions and momentum, the solutions can be formulated into new law or amendments to existing law.

Brody (1998) notes some of the problems that have resulted in the development of human subjects protection policy: (1) cases of research that generated controversy, e.g., Nazi doctor experiments, Tuskegee experiments, Henry Beecher's article in the New England Journal of Medicine describing widespread unethical practices in medical experimentation; (2) public or professional concerns about the research components of dramatic new technologies, e.g., genetic engineering; (3) broader social concerns, e.g., inclusion of women and minorities in research (p. 198). Another impetus for policy formulation is a nation's intent to meet the membership requirements of an international organization, such as the European Union (EU), that mandates the adoption of its bioethical standards into national law.

Just because a law is passed does not mean it will be put into effect. It has to be implemented. Regulations and guidelines are needed to clarify the often-vague legislative language and establish the routines and standard operating procedures of the program, i.e., the vehicle for accomplishing the policy's goals. Implementation is the purposeful, organized activity that transforms a policy into a program and the latter into program outputs corresponding to intended objectives (Rettig, 1980). Here officials of national governmental 
agencies and those responsible for operating RECs play an important role not only as implementers but as program managers, that is, those who are responsible for achieving intended objectives on an ongoing basis. Critical to program management are the administrative procedures that establish mechanisms for accountability and the assessment of program accomplishment.

What are the outcomes of the policy? Are they positive as intended? Are they negative, e.g., overregulation that stifles research? Presumably, if performance slips below some threshold, those involved in policymaking and program management will modify the policy (as shown in Figure 1 by the arrows leading back to policy formulation and policy implementation). Factors triggering policy modification include those mentioned by Brody, often shaped by research of a policy-relevant nature. Also, routine monitoring, review, and evaluation of programs may result in their incremental modification or major reorientation (Rettig, 1980). In some instances there may be a formal mechanism governing policy modification as is the case with the rule-making process and the revision of the federal Common Rule establishing the regulatory framework for research ethics review in the United States (US Department of Health and Human Services, 2011).

As an analogy to policy implementation and modification, we can imagine that the formulation of official public policy delineating the intended program is like an architect's sketch of a building. Someone has to turn the sketch into more detailed plans, construct the building, and maintain the building for the purpose for which it was constructed. We can ask whether the sketch is clear enough and complete enough to inform the construction? Did the architect leave out any critical piece necessary for the success of the building? How much of the building has been actually constructed and to what extent does it match the architect's original intentions? And if it does not match, what do the architects, construction engineers, and building users know or care about it and what modifications or corrective actions will they take, if any?

\section{The logic model as the framework for analyzing policy and program gaps}

The questions raised about the building design and construction process are the same types of questions we would like to ask about human research subjects protection systems. To frame these questions we employ a logic model depicting policy as a flow of inputs, throughputs, outputs, and outcomes as shown in Figure 2 (Wholey, 1983). In doing so we conceptualize policy as a theory or hypothesis. To be tested are the causal connections between means and ends of the causal chain, e.g., testing the assumption if we do $A B C$ at time 1, XYZ will result at time 2 (Thompson, 1983).

What are sources of information useful for describing the policy and program? We can start with publicly available information including international and national laws, regulations, and guidelines; policies, standard operating procedures (SOPs) of individual RECs and their parent institutions; reports, audits, and other materials produced by governmental agencies, professional associations, or NGOs; and scholarly publications. At a minimum we can determine the country's official policy and the extent that it incorporates international 
standards from authoritative documents stipulating how RECs are supposed to function, essential information for constructing the logic model.

More specific to program management, we may also be able to discover how agencies that are charged with overseeing RECs are supposed to assess REC performance and take corrective action for inferior performance. Organization charts, in addition to depicting the path of scientific protocol review and approval, document the formal hierarchical arrangements and direct and indirect reporting relationship among the organizational elements that make up the program. Of course a bold line on paper, connecting two organizational units at different hierarchical levels and thereby expressing their intended relationship, may in reality be quite thin or even nonexistent. But this knowledge is often an important part of the analysis.

Ideally we would like to interview key informants among policymakers, program managers, and important stakeholders and conduct surveys of RECs functioning at the national, regional, or institutional level. However, this type of information is often difficult to collect.

In Figure 2, the research ethics system is modeled as a causal chain leading to the desired ends or goals: the protection of human research subjects. The basic components of this chain are inputs (laws and regulations) that establish the REC structure with such requirements as membership composition and level of training and the process that includes the review criteria and how they are to be applied to individual cases. The products or outputs of the process are the decisions to approve or deny (e.g., the number and types of protocols reviewed and the approval status).

While there are numerous regulations, guidelines, and accreditation criteria that provide standards and benchmarks for establishing and assessing the adequacy of structure and process, the assessment of outcomes is more problematic (Sleem et al., 2010). Coleman and Bouësseau (2008) suggest that the assessment of performance address six questions. Does the REC review process: (1) improve participant's understanding of the risks and potential benefits of studies? (2) affect prospective participant's decisions about whether to participate in research? (3) change participant's subjective experiences in studies or their attitudes about research? (4) reduce the riskiness of research? (5) result in more research responsive to the local community's self-identified needs? and (6) result in REC guidance that is actually being followed by researchers?

In most cases, the outcome questions suggested by Coleman and Bouësseau are not asked or answered in any systematic way. As is often the case with the measurement of quality of medical care, assessors rely on structural and process measures as proxies for desired outcomes (Donabedian, 1964). But as Baruch Brody (1998) reminds us, "In truth, we know little about the actual quality of independent ethical review of research, and even less about how that quality varies with different structures and different functions of the independent review committee" (p. 43).

How policymakers, program managers, and other stakeholders perceive or identify gaps between what is intended to happen in the causal chain, expressed through law and 
regulation (inputs), and what actually happens depends on what evidence they accept as convincing that the policy is succeeding in protecting human research subjects.

The policymakers are simply the makers of laws, regulations, guidelines, and budgets. They include, in addition to legislators and elected officials, political appointees and bureaucrats. To be sure, to a certain extent officials in governmental agencies and also at the REC level overlap in their policymaking and program management roles. Most interesting to us are those who have power and influence over inputs. They are those to whom, if we were given the chance, we would like to ask the question of what constitutes convincing evidence to them that the program is working or not working. And if, according to their criteria, the program is not working, what steps would or could they take?

There are undoubtedly policymakers, program managers, and powerful stakeholders who, even if they officially subscribe to the measures mentioned above, would judge the human research subjects protection policy a success merely if the pharmaceutical industry were able to maintain or increase its clinical research presence in the country or at a particular institution without the occurrence of a major scandal. For them and for many others, adherence to international guidelines, accreditation criteria, or Coleman and Bouësseau's suggested outcome measures would not be required as convincing evidence of policy effectiveness or failure. Nevertheless, the advantage of our systems approach is that it does not let us lose sight of the intended linkages, even if aspirational, between the official policy goals and structure, process, and outcomes measures. And of course researchers, policy evaluators, advocates, and other stakeholders may choose to use these or other measures of effectiveness to make a case for policy modification.

Those wishing to modify policy, in making their case, identify gaps in the causal chain by raising questions related to implementation and plausibility (Thompson, 1983). For example, with regard to implementation, it is commonly the case that REC members are inadequately trained and supported and therefore cannot appropriately carry out ethical review. In other words, $X Y Z$ did not result because $A B C$ did not happen.

Even if the policy is implemented successfully, is there reason to believe that the policy can achieve its outcomes? There may be critical policy pieces or building blocks left out of the original blueprint during policy formulation. For example, Gefenas et al. (2010) highlight the asymmetries in the stringency of ethical review for clinical drug trials (CDT) versus nonCDT research (e.g., the testing of cardio-surgical procedures). While all EU countries have adopted the Clinical Trials Directive into law, some countries from Central and Eastern Europe still lack laws providing safeguards for participants in non-CDT research, even though this research may present risks similar to CDT research. Given the lack of national policy addressing this type of research, Gefenas et al. question the plausibility of research subjects being protected from physical or psychological harms.

\section{Program management}

Figure 3 expands the logic model to highlight the role of program management and differentiate it from policy-making. In our model, program management is to be found at two different levels: (1) the institutional, regional, or national organizations that directly 
operate RECs; (2) national-level organizations (e.g., national bioethics commission, agencies of the ministry of health) that oversee and support the entire system of RECs.

Ethical review is carried out by institutional, regional, or national RECs. As an example, the Rector of the University of Tartu, drawing upon various Estonian constitutional provisions and laws, established an institutional REC. The university's own statute establishing its REC delineates in detail the REC's mission, jurisdiction, financing, structure, process, and other operational procedures. All of this is publicized on the university's website (www.ut.ee/en/ research-ethics-committee-university-tartu). The rector is the chief academic and administrative officer under whose authority the REC was established. Working within the university governance structure, the rector is ultimately responsible for the REC according to national and university policy, although this responsibility is usually delegated to others in the organization. Research ethics review requires university commitment to providing adequate organizational structure, budget, staffing, training, oversight, and other forms of institutional support, material or symbolic.

At the national level, program management roles are carried out by governmental agencies. Much of governmental activity is regulatory in nature, for example, the use of monitoring, sanctions, and so forth to achieve compliance with regulations. But the intention to build research ethics capacity and strengthen the various levels of REC review on a nationwide basis may also be part of the mission. To do their job, these governmental agencies must be given adequate authority and resources.

As an example of national-level program management, the Lithuanian Bioethics Committee, accountable to the Ministry of Health, exercises oversight over regional RECs. The mission of the Lithuanian Bioethics Committee also includes consultation, education, and advocacy with regard to protecting human research subjects. Additionally, the Lithuanian Bioethics Committee conducts ethical review of certain kinds of clinical drug trials as an independent "national-level REC" and as such occupies space in two parts of the model (Lithuanian Bioethics Committee, 2013).

The model shows public policy as a flow of "inputs." Central to the definition of a program is the idea that inputs need to be "managed" toward the policy ends. To what extent is somebody or some body doing the managing? Presumably program managers have some responsibility for making sure that research ethics review is in fact leading to the protection of human subjects and are accountable for the results to a higher level of authority. Relevant here is the capacity of national-level program management, juxtaposed between policymaking and the REC review process. (In the United States, this conceptual space is occupied by the Office for Human Research Protections, which holds the ultimate power, occasionally exercised, to withdraw government funding and stop research.) Do nationallevel program managers have adequate power? Do they have the appropriate tools and are they using them? Even if they have agreed-upon structural or process measures of performance as proxies for outcomes, is there anything they could possibly do with that performance information to improve performance by taking corrective action (e.g., employing sanctions)? Do they engage the feedback arrows in the public policymaking process model? 
The model in Figure 3 also includes negative outcomes such as overregulation. To be noted is the tension that exists between two kinds of errors: (1) those of stringency, where human subjects are protected to such a degree that advancement of knowledge is blocked or made more inefficient; (2) those of liberality, where researchers harm human subjects. The objective of policymakers and program managers should be to find some reasonable balance in efforts to avoid the two kinds of errors (Thompson, 1983).

Is there any evidence of even a minimum level of monitoring of REC structure, process, outputs, or outcomes? There may be evidence to the contrary. For example, Czarkowski and Rozanowski (2009) report that Polish RECs do not have any legal obligation to report on their work to higher authorities. Without information, how can there plausibly be follow-up? Czarkowski and Rozanowski conclude that RECs in Poland are completely independent and there is no central institution that could oversee or monitor their work.

Sometimes programs are found to be hollow shells floundering in an indifferent or hostile environment unsupported by the enabling conditions described by Hyder et al. In short, policies that are on the books may produce little more than a "Potemkin village." Of course, a "Potemkin village" might be all that some require as their evidence of policy success.

To sum up, to apply the logic model framework in analyzing a research ethics review system, first describe the public policy's causal chain, from inputs to outcomes, that is supposed to achieve the official goals as delineated in authoritative documents. Next, compare the rhetoric to the reality and identify gaps in terms of plausibility. To the extent there is available information, determine how much of the program has been implemented as planned.

In the same way, the evaluator can make a judgment about the capacity and willingness of policymakers and program managers to measure REC performance and take corrective action. This assessment can be used as a springboard for making recommendations for filling the gaps, changing unrealistic outcome expectations, and/or planning more in-depth research analyzing the relationship between outcomes and earlier activities in the logic chain.

Ultimately the logic model analysis can be useful in planning a program evaluation. The greater the agreement among policymakers and program managers on performance measures and uses of performance information, the greater the likelihood the program evaluation will produce convincing evidence on policy effectiveness (Wholey, 1979).

\section{Examples from belarus}

Based on a review of public documents and a survey of RECs, Famenka, an alumnus of the Advanced Certificate Program, described the research ethics review system in Belarus and identified deficiencies in policy implementation and plausibility (Famenka, 2011, 2014).

Belarus (population 9.5 million) and Russia are the only countries in Europe considered "not free" in terms of competitive elections, civil liberties, free press, and independent civic life according to Freedom House's annual "Freedom in the World Survey" (2011). On 
Transparency International's Corruption Perceptions Index, Belarus is one of the more corrupt countries in the region (Transparency International, 2012). It is not a member of the European Union or the Council of Europe and therefore not subject to their standards. In short, Belarus would rank low on the enabling and developmental conditions mentioned by Hyder et al. Famenka's efforts to systematically describe the research ethics review system and highlight major problems and challenges are among the first in the country.

\section{Policy Formulation}

In Belarus, the formulation of public policy for human research subjects protection was driven by the government's desire to foster the national health research enterprise and open up the market for multicenter clinical drug trials. In effect, Belarus needed to show international research sponsors that it could comply with the requirements of the principles of Good Clinical Practice (GCP). To achieve this end, Belarus passed laws that incorporated the majority of the international standards on research ethics.

Because the intention of the laws was to meet the formal requirements of the clinical drug trials industry, the review and approval process is limited to clinical drug trials. Protection of human subjects in nonclinical trials was not part of the original plan.

\section{Policy Implementation}

The laws, together with Ministry of Health regulations augmenting and implementing the laws, produced a research ethics review system represented by the organizational chart shown in Figure 4. The chart displays the major organizational entities in the research ethics review system and the hierarchical relationships among them. Embedded in various hospitals, polyclinics, universities, and research institutions are over 50 RECs responsible for reviewing clinical drug trial protocols and making recommendations to the Center for Clinical Trials and the Commission on Pharmaceuticals (competent authorities) for approval, which in turn send their recommendations to the Ministry of Health for final approval. In complying with the various international requirements, the RECs of Belarus would have to put into place the structures and processes appropriate for effective ethical review leading to the protection of human research subjects. Because of the lack of transparency, Famenka had little direct knowledge of individual RECs and the institutions that establish and host them. The response rate from his survey of RECs was low and none had public websites or issued periodic reports.

Legislation and regulation are silent on formal requirements for initial training and ongoing education of REC members. However, REC member knowledge of research ethics, a critical ingredient for the review process, is not likely to be high given the low attention paid to bioethics at undergraduate and postgraduate levels of medical education (Kubar, 2010). Legislation and regulation have no provision for the financial support of RECs, leading Famenka to conclude that RECs are not supposed to collect fees for review, have an operational budget, or pay members for their work.

An important purpose of the model displayed in Figure 3 is to raise questions concerning the capacity of program management at the national and institutional levels. At the national level, the Ministry of Health established the National Bioethics Committee (NBC) to 
coordinate and oversee the activity of RECs, serve as an appeals body regarding REC decisions, and serve as a source of consultation and technical advice. However, Famenka, in examining the Ministry of Health regulations implementing the NBC, found that the ministry provided no tools and no concrete support to carry out assigned functions, thus rendering an "on paper" existence only for the NBC. During its six-year history the NBC has shown only sporadic activity: it has not produced a single policy paper, opinion, or recommendation. With no procedures for audit and monitoring, and no requirements for RECs to inform the public about their most important activities, the line of accountability on the organization chart connecting the RECs to the NBC and upward to the Ministry of Health and presumably to the Legislature has effectively been erased.

\section{Policy Outputs and Outcomes}

Famenka found no public information on Belarus REC decisions with regard to how many and what types of protocols were reviewed and whether to approve, reject, or modify. Nevertheless, he was able to draw some conclusions about the research ethics review structure and process and, by implication, outcomes.

Peculiar to Belarus is its structuring of RECs. One of the basic tenets of research ethics review is that the effects of conflict of interest among REC members should be minimized. To this end, most international standards require some outside representation on institutional review boards. Deviating from international standards, Belarus's official policy states that an REC should be composed of employees of the health care organization that establishes it (Famenka, 2011). Given the constraints of a deficient structure mandated by public policy (i.e., membership composition of the REC), and based on the deficiencies in REC training, lack of oversight, the level of corruption in the general society, and the proclivity to accommodate the pharmaceutical industry in the expansion of clinical drug trials, Famenka questioned the likelihood of the REC undertaking a thorough, independent, and unbiased review process leading to the protection of human research subjects.

In summary, although rhetorically research ethics review is supposed to be a central tenet of Belarus policy for the human research subjects protection, the program has been deprived of necessary "inputs." To begin with, Famenka found obvious deficiencies in laws and regulations with regard to the protection of non-CDT subjects. Even with regard to the protection of CDT subjects, the structure and process of ethical review are unsupported or flawed due to aberrant national legislation. Finally, the main mechanisms of what we call national-level program management have not been implemented.

\section{Next steps: policy modification}

A key challenge is to get policymakers to pay attention to the findings from reports and published research describing and evaluating the research ethics system of a country. The job for those seeking change is to craft and present the research in such a way so as to trigger the policy modification phase of the public policymaking process. Linkages of researchers to policymakers can prove helpful. For example, in 2007, the Polish Chamber of Physicians and Dentists, an official organ of the state that regulates physicians and dentists and advises Parliament, formed the Center for Bioethics of the Supreme Medical Council of 
Poland under the leadership of Dr. Marek Czarkowski, who was an Advanced Certificate Program fellow at that time. Among its functions are to undertake research on bioethical issues in Poland and to focus attention on gaps in laws, regulations, and practices and to make recommendations.

Of course there is justified skepticism about the ability of evaluation research to make much of an impact on the policymaking process in the absence of a major scandal attracting media attention. Nevertheless, although the likelihood of directly impacting policymakers is often low, there are indirect means of influence operating through a policy community (Walt, 1994). A policy community is composed of those groups that have a stake in the results of the public policymaking process. They are not necessarily homogeneous in their perspective. As interest groups they attempt to influence the public policymaking process.

The policy community for a country's research ethics review system might include international organizations, professional and academic associations, NGOs, and religious bodies. The pharmaceutical industry, universities, and research organizations, key players in the biomedical research enterprise, also have a stake in the policies affecting the research ethics review system.

Many of the Advanced Certificate Program alumni go on to participate in organizations that can be considered part of the policy community on the national, regional, and international levels and to serve in national and institutional program management positions (Strosberg et al., 2013). Walt (1994) notes:

The main point about a policy community is that there is a constant exchange of information about activities and ideas, and that some of these reach government policy makers. Policy communities provide a number of different fora in which the early stages of opinion formation and consensus building among experts takes place (scientific meetings, journals, newspapers) although it may take years for ideas to diffuse broadly, especially where they are critical of existing policy (p. 110).

The expectations of researchers who are critical of existing policy and wish to promote change must be calibrated to the constraints faced by post-Soviet transition societies. These constraints are the limitations in the enabling and developmental conditions mentioned by Hyder et al. having to do with civil society, public accountability, transparency, trust in basic transactional processes, political freedom, etc. In this regard, post-Soviet transition countries vary greatly. For example, Russia, a non-EU member with a population of 142 million and Transparency International (2012) Corruption Perceptions Index (CPI) of 28, is next door to Estonia with a population of 1.3 million and a CPI of 64 on a scale of 1-100. (Nearby Finland's CPI is 90.) The ability of groups within the policy community to promote change is related to the robustness of civil society and the openness of the political system to participation. 


\section{Educational Implications}

Fellows in the Advanced Certificate Program in Research Ethics for Central and Eastern Europe, composed of seven graduate courses taken in a hybrid online onsite mode, participate in an exercise applying the logic model framework to their home countries (Strosberg et al., 2013). Based on publicly available documents and published materials, they make a first attempt at constructing a logic model and identifying policy and program gaps and weaknesses. The online platform facilitates interactive discussion comparing the findings from the various countries. Later on in the curriculum, in fulfillment of the requirement for a final project, some Advanced Certificate Program fellows choose to conduct a more comprehensive analysis using the framework advocated in this paper. Others choose to more narrowly concentrate on studying a particular gap and making recommendations for closure. In both cases, study findings are presented at academic and professional conferences or published in journals.

The framework may hold interest for other FIC programs. In 2012, two FIC programs serving the post-Communist countries conducted a survey of their 54 alumni from 14 different countries (87\% response rate). From the survey, Table 1 summarizes alumni perceptions of key barriers to building research ethics capacity (Strosberg et al., 2013, p. 35). (The table was constructed with the components of the Hyder et al. model in mind.) Although the table concerns post-Communist countries, it is likely that many of the same barriers exist in the other areas of the world covered by FIC programs. Alumni who go on to serve not only as REC members and leaders but as program managers, policymakers, and participants in the policy community will undoubtedly confront many of these barriers.

Based on the public policy and public management literature, the logic model analytical framework presented in this paper is meant to show the ways by which these barriers create gaps in the causal chain leading to the accomplishment of policy objectives and place constraints on the public policymaking process. The utility of the framework is shown by the Belarus case, an analysis that was necessarily conducted at the " 40,000 -foot level" under conditions of extremely limited transparency. However, it is generalizable to other countries served by FIC programs where analysts may have the opportunity to probe much more deeply and extensively. Regardless of the depth of the analysis, the application of the framework is a useful exercise that could be adopted by other FIC programs.

\section{Acknowledgments}

The project described herein was made possible by grant R25 TW007085 (E-Education in Research Ethics: Central and Eastern Europe). The authors thank Barbara Sina and Joseph Millum for their helpful suggestions on the manuscript. The contents of this report are solely the responsibility of the authors and do not necessarily represent the official view of the NIH.

\section{References}

Advanced Certificate Program in Research Ethics for Central and Eastern Europe. Union Graduate College and Vilnius University; researchethicseurope.com

Brody, BA. The ethics of biomedical research: An international perspective. New York: Oxford University Press; 1998. 
Coleman $\mathrm{CH}$, Bouësseau M-C. How do we know that research ethics committees are really working? The neglected role of outcomes assessment in research ethics review. BMC Medical Ethics. 2008; 9:6. [PubMed: 18373857]

Czarkowski M, Rozanowski K. Polish research ethics committees in the European Union system of assessing medical experiments. Science and Engineering Ethics. 2009; 15:201-212. [PubMed: 19156538]

Donabedian A. Evaluating the quality of medical care. Milbank Memorial Fund Quarterly: Health and Society. 1964; 44(3 Suppl):166-206.

Famenka A. Ethical review of biomedical research in Belarus: Current status, problems and perspectives. Romanian Journal of Bioethics. 2011; 9(2):74-83. [PubMed: 22701397]

Famenka A. in preparation. Research ethics in the context of transition: An analysis of policies and programs on the protection of human research subjects in the selected countries of Central and Eastern Europe. 2014

Gefenas E, Dranseika V, Cekanauskaite A, Hug K, Mezinska S, Peicius E, et al. Non-equivalent stringency of ethical review in the Baltic states: A sign of a systematic problem in Europe? Journal of Medical Ethics. 2010; 36:435-439. [PubMed: 20606000]

Fogarty International Center, National Institutes of Health. International research ethics and curriculum development award. 2013. Retrieved from www.fic.nih.gov/programs/pages/ bioethics.aspx

Freedom House. Freedom in the world: The authoritarian challenge to democracy. 2011. Retrieved from www.freedomhouse.org/report/freedom-world-2011/essay-freedom-world-2011authoritarian-challenge-democracy

Hyder AA, Dawson L, Bachani AM, Lavery J. Moving from research ethics review to research ethics systems in low-income and middle-income countries. Lancet. 2009; 373:862-865. [PubMed: 19269523]

Kingdon, JW. Agendas, alternatives, and public policies. New York: HarperCollins College; 1995.

Kubar, O. The current state of bioethics education in the system of medical education in the CIS member states. Saint Petersburg: Pasteur Institute; 2010. p. 24-26.30-32

Lithuanian Bioethics Committee. 2013. Retrieved from http://bioetika.sam.lt/index.php?2084126709

Longest, BB. Health policymaking in the United States. Chicago: Health Administration Press; 2010.

Rettig, RA. Implementing the end-stage renal disease program of Medicare (R-2505-HCFA/HEW, September 1980). Rand Corporation; 1980. Retrieved from www.rand.org/content/dam/rand/pubs/ reports/2005/R2505.pdf

Sleem H, Abdelhai R, Al-Abdallat I, Al-Naif M, Gabr H, Kehil E, et al. Development of an accessible self-assessment tool for research ethics committees in developing countries. Journal of Empirical Research on Human Research Ethics. 2010; 5(3):85-98. [PubMed: 20831423]

Strosberg MA, Gefenas E, Loue S, Philpott S. Building research ethics capacity in post-communist countries: The experience of two Fogarty training programs. Journal of Empirical Research on Human Research Ethics. 2013; 8:28-39. [PubMed: 24384514]

Thompson, FJ. Health policy and the bureaucracy: Politics and implementation. Cambridge, MA: MIT Press; 1983.

Transparency International. Corruption Perceptions Index. 2012. Retrieved from www.transparency.org

US Department of Health and Human Services. ANPRM frequently asked questions (FAQs) July 2011. 2011. Retrieved from www.hhs.gov/ohrp/humansubjects/anprmqanda.html

W. K. Kellogg Foundation. Logic model development guide. Battle Creek, MI: W. K. Kellogg Foundation; 2004.

Walt, G. Health policy: An introduction to process and power. London: Zed Books; 1994.

Wholey, J. Evaluation and effective public management. Boston: Little, Brown; 1983.

Wholey, J. Evaluation: Promise and performance. Washington, DC: Urban Institute; 1979. 


\section{Biographies}

Martin Strosberg is Professor of Bioethics and Healthcare Policy at the Center for Bioethics and Clinical Leadership of Union Graduate College. His interests are in public policy and management. He had overall responsibility for the writing of the manuscript. He is co-director of the Advanced Certificate Program in Research Ethics for Central and Eastern Europe.

Eugenijus Gefenas is Associate Professor and Director of the Department of Medical History and Ethics at the Medical Faculty of Vilnius University. The areas of his professional interest include the ethical, philosophical, and public policymaking issues related to human research. His role in this paper was to edit the paper in collaboration with other authors. He is co-director of the Advanced Certificate Program in Research Ethics for Central and Eastern Europe.

Andrei Famenka is Legal Medicine Specialist at the State Service of Legal Medicine of the Republic of Belarus. His interests are in health law, biomedical ethics, and public policy. He was responsible for the section on Belarus. 


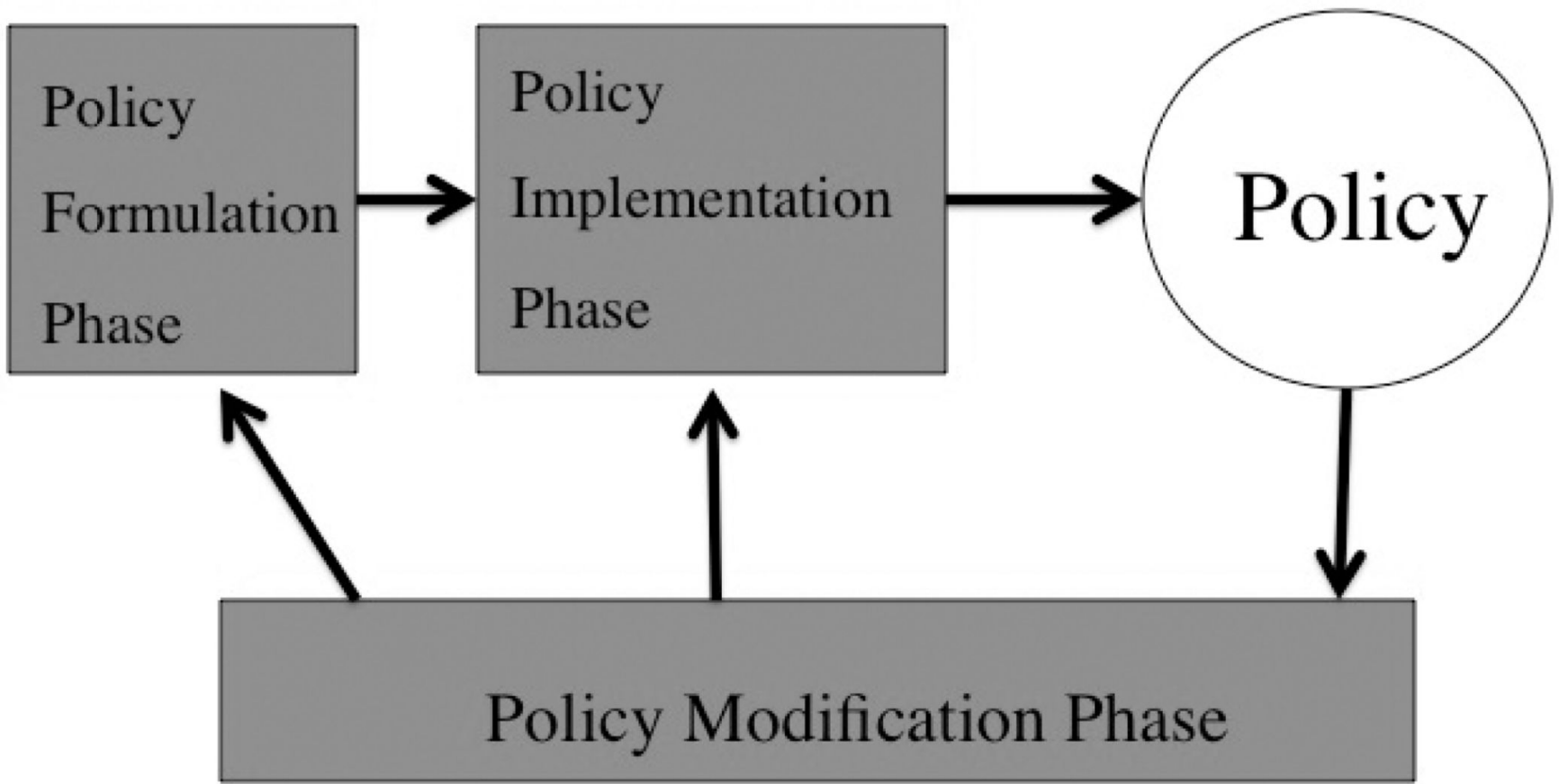

Adapted from B.B. Longest, Health Policymaking in the United States. Chicago: Health Administration Press, 2010

Fig. 1.

Public policymaking process. 


\section{Inputs $=>$}

Structure/

Process $\Rightarrow>$

\begin{tabular}{l|l|l|l|}
$\begin{array}{l}\text { Laws } \\
\text { Regs }\end{array}$ & $\begin{array}{l}\text { REC } \\
\text { jurisdiction, } \\
\text { Funds }\end{array}$ & $\begin{array}{l}\text { Reviewed } \\
\text { protocols } \\
\text { SOPs }\end{array}$ & $\begin{array}{l}\text { Protected } \\
\text { human subjects }\end{array}$ \\
$\begin{array}{l}\text { Other } \\
\text { resources }\end{array}$ & Ethical review & & $\begin{array}{l}\text { (Negative } \\
\text { outcomes, e.g., } \\
\text { overregulation) }\end{array}$
\end{tabular}

Fig. 2.

Logic model of human research subjects protection policy. 
Policy Making:

Inputs - Directives, Laws,

Regulations, Guidelines

Budget

Other resources
National-level Program Management

(e.g., oversight, consultation, support for REC system)

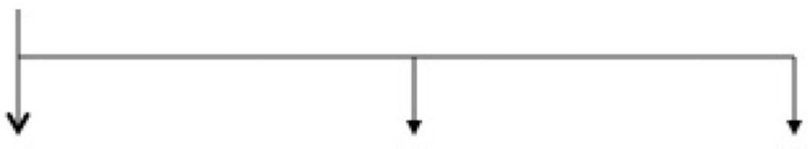

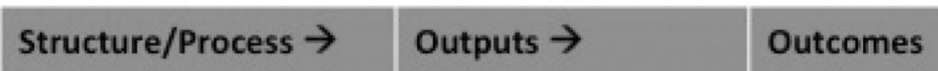

REC jurisdiction, composition, SOPS

Reviewed protocols

Ethical review

Scientific review

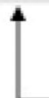

Program Management of individual

National, Regional, or Institutional RECs

Fig. 3.

Policy and program for research ethics review. 


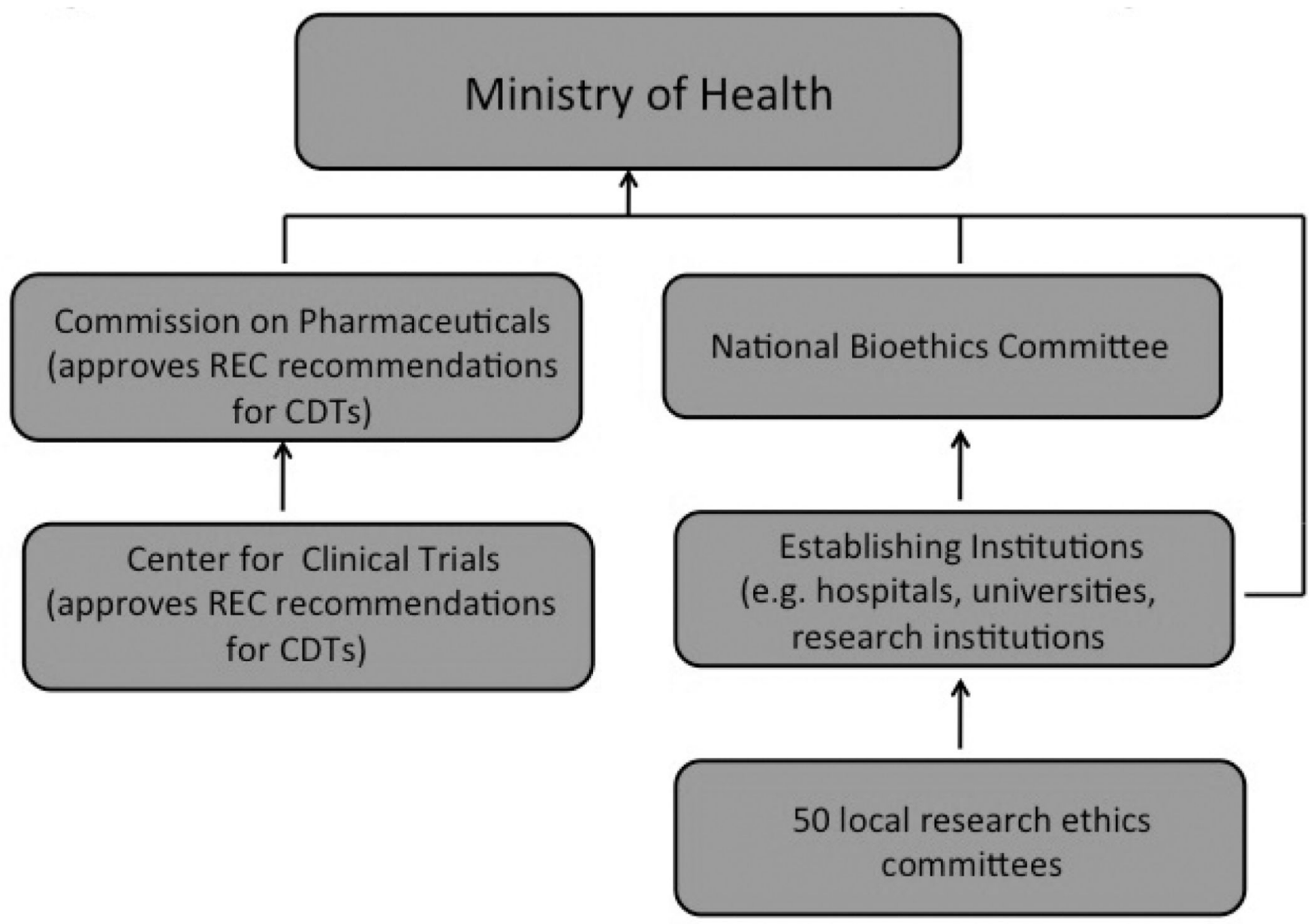

Fig. 4.

Belarus research ethics review system-org. chart. 


\section{TABLE 1}

Union Graduate College-Vilnius University and Case Western Reserve University Alumni Perceptions on Barriers to Building Research Ethics Capacity in Post-Communist Countries (Strosberg et al., 2013, p. 35).

\begin{tabular}{|c|c|}
\hline Component Model Category & Perceived Barrier \\
\hline \multirow[t]{6}{*}{ Enabling and Developmental Conditions } & Decision making driven by economics \\
\hline & Legal nihilism \\
\hline & Lack of public transparency \\
\hline & Medical paternalism \\
\hline & Political, judicial, and institutional corruption \\
\hline & Lack of human rights for stigmatized and vulnerable populations \\
\hline \multirow[t]{4}{*}{ National and Institutional Commitment } & Lack of research ethics legislation and policies \\
\hline & Lack of regulatory enforcement \\
\hline & Lack of institutional support for RECs \\
\hline & Lack of an organized structure to collect information on REC effectiveness \\
\hline \multirow[t]{3}{*}{ Clinical Researcher Conduct } & Inadequate knowledge and training \\
\hline & Lack of funding for research ethics training programs \\
\hline & Uncontrolled conflicts of interest \\
\hline \multirow[t]{3}{*}{ REC Expertise and Commitment } & Lack of transparency in appointments and review \\
\hline & Lack of procedural and regulatory clarity \\
\hline & Lack of training of REC members \\
\hline
\end{tabular}

